\title{
Role of Intraoperative Transesophageal Echocardiography in the Management of Renal Cell Carcinoma with Cavoatrial
} Extension

\author{
Sunder L Negi ${ }^{1}$, Krishna P Gourav², Ganesh K Munirathinam ${ }^{3}$, Goverdhan D Puri ${ }^{4}$, Subhrashis G Niyogi ${ }^{5}$, Vamsi Dar $^{6}$
}

\begin{abstract}
In all, 4-10\% of tumor thrombus in renal cell carcinoma (RCC) extends into the inferior vena cava (IVC). When the thrombus extends into the right atrium (RA), it becomes surgically challenging; and depending on its extension and adherence to the underlying structure, it may need cardiopulmonary bypass (CPB). The utility of transesophageal echocardiography (TEE) is reviewed for the management of RCC with cavoatrial extension. Intraoperative TEE is an essential modality in cases of RCC with level IV tumor thrombus, and in cases that require CPB with or without deep hypothermic circulatory arrest (DHCA). Intraoperative TEE provides us real-time information about thrombus staging in addition to the properties of the thrombus, such as adherence and fragility. Intraoperative TEE can also be used to assess cardiac function, fluid status, real-time monitoring of thrombus including embolization while manipulation and to ensure no residual thrombus. We therefore recommend the use of intraoperative TEE in RCC with level IV tumor thrombus. In the future, more research is needed to demonstrate the impact of intraoperative TEE on morbidity, mortality, and complication rate of the procedures.

Keywords: Cardiac extension, Renal cell carcinoma, Transesophageal echocardiography.

Journal of Perioperative Echocardiography (2019): 10.5005/jp-journals-10034-1099
\end{abstract}

\section{INTRODUCTION}

The most common malignant tumor of the kidney is renal cell carcinoma (RCC), and it has biological propensity to invade venous channel, which can extend into the inferior vena cava (IVC). ${ }^{1}$ The incidence of RCC with IVC extension is 4-10\%, ${ }^{2-4}$ while the incidence of extension of RCC in to the right atrium (RA) is almost $1 \%$. A small percentage of these thrombi can further extend into the right ventricle through the tricuspid valve. ${ }^{5,6}$

The RCC has been classified by Neves and Zincke based on their cephalic extension.? In level I RCC, tumors extend less than 2 $\mathrm{cm}$ above the renal vein. In level II RCC, tumors extend more than $2 \mathrm{~cm}$ above the renal vein while remaining infrahepatic. In level III RCC, tumors extend into the retrohepatic IVC. However, in level IV RCC, tumors extend into the RA.

The RCC with level IV extension presents a challenge to surgeon and anesthesiologist during intraoperative period as the tumor thrombus extends into the RA with various degrees of infiltration and adherence into the underlying structures. Total circulatory arrest should be considered, because under these circumstances it allows us with direct visualization of the vena caval lumen in bloodless surgical field and allows us to safely remove the thrombus. ${ }^{8,9}$ It also decreases the risk of embolization into the pulmonary circulation. The incidence of pulmonary embolism is $3.5 \%$ and is associated with $75 \%$ mortality. ${ }^{10}$ In RCC with level IV thrombi, the wall of the IVC is usually infiltrated by tumor, complete clearance is only possible with instituting bloodless field, and is difficult to achieve complete removal of tumor thrombus with traction and blunt dissection.

\section{Preoperative Imaging}

Preoperative evaluation of RCC with atrial extension is essential for optimal surgical planning. So far the best available imaging modality for RCC with cavoatrial extension is the magnetic resonance imaging

\begin{abstract}
${ }^{1-5}$ Department of Anesthesia and Intensive Care, Postgraduate Institute of Medical Education and Research, Chandigarh, India

${ }^{6}$ Department of Anesthesia and Intensive Care, Andhra Medical College, Nellore, Andhra Pradesh, India

Corresponding Author: Sunder L Negi, Department of Anesthesia and Intensive Care, Postgraduate Institute of Medical Education and Research, Chandigarh, India, Phone: +91 9888446388, e-mail: dr. sundernegi@gmail.com
\end{abstract}

How to cite this article: Negi SL, Gourav KP, Munirathinam GK, et al. Role of Intraoperative Transesophageal Echocardiography in the Management of Renal Cell Carcinoma with Cavoatrial Extension. J Perioper Echocardiogr 2019;7(1):2-5.

Source of support: Nil

Conflict of interest: None

(MRI), which has been considered as a gold standard imaging modality. ${ }^{11}$ However, its cost and limited accessibility may limit MRI use in clinical practice. ${ }^{12}$ Some studies have demonstrated that computed tomography (CT) has comparable accuracy in diagnosing tumor and its extension. ${ }^{13}$ If possible, MRI or CT should be performed within 14 days of the surgical intervention and advised not to do 30 days before the operation ${ }^{14}$ due to the risk of further tumor extension between imaging and the surgical intervention. Intraoperative transesophageal echocardiography (TEE) is another key imaging modality that can provide us additional real-time information during perioperative period. It efficiently evaluates and precisely defines the cephalic extension of tumor thrombus. The TEE is an important imaging modality in perioperative period which tells us about the nature of tumor thrombus, and it includes tumor consistency, fragility, adherence, and mobility, which are very crucial in formulating the surgical approach (Fig. 1). ${ }^{15-17}$ Current guidelines given by the American College of Radiology in 2016 are not recommending the use of echocardiography in RCC with caval

(-) The Author(s). 2019 Open Access This article is distributed under the terms of the Creative Commons Attribution 4.0 International License (https://creativecommons. org/licenses/by-nc/4.0/), which permits unrestricted use, distribution, and non-commercial reproduction in any medium, provided you give appropriate credit to the original author(s) and the source, provide a link to the Creative Commons license, and indicate if changes were made. The Creative Commons Public Domain Dedication waiver (http://creativecommons.org/publicdomain/zero/1.0/) applies to the data made available in this article, unless otherwise stated. 


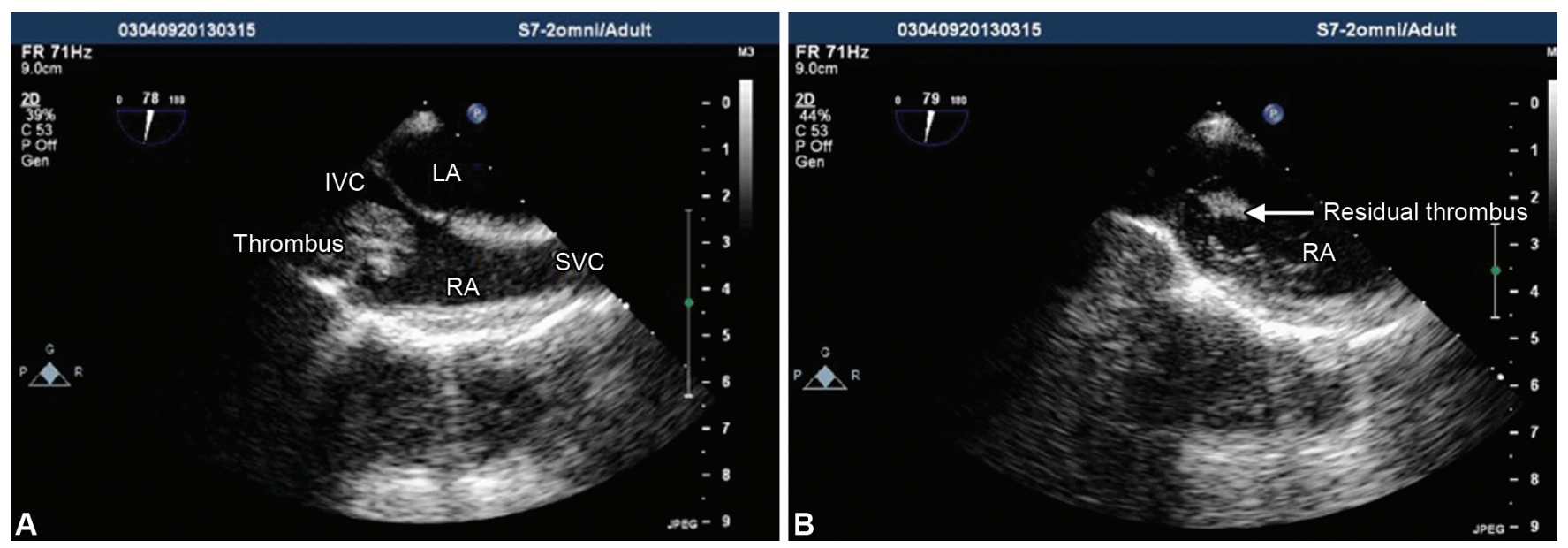

Figs 1 A and B: A 57-year-old male with a right renal mass consistent with renal cell carcinoma extending into right atrium. (A) Intraoperative transesophageal echocardiography (TEE) showed a large, mobile tumor thrombus extending from the inferior vena cava (IVC) into the right atrium; (B) Intraoperative TEE showing residual tumor thrombus in right atrium following thrombus retraction from IVC. SVC, superior vena cava

extension. However, it is performed at the discretion of a surgeon or anesthesiologist. It has been reported that preoperative TEE has no added diagnostic advantage over MRI. ${ }^{17}$ However, there are some case reports where TEE detected cavoatrial extension of RCC which was primarily missed on MRI. ${ }^{18}$

\section{Intraoperative Imaging}

Intraoperative TEE monitoring has been very frequently used in liver transplant surgeries ${ }^{19}$ and also been described in noncardiac surgeries such as orthopedic and neurosurgery patients, where there is an increased risk of fat and air embolism. ${ }^{20-22}$ However, intraoperative TEE is primarily used as a monitoring tool or as a rescue procedure in $\mathrm{RCC}$ with cavoatrial extension. ${ }^{23}$ Comprehensive baseline examination should be performed to look for biventricular function, valvular assessment, any shunt lesion across the septum, regional wall motion abnormalities, and characteristics of the main pulmonary artery, right pulmonary artery, and proximal left pulmonary artery as described by the guidelines in the American Society of Echocardiography. To appreciate subtle changes in intraoperative period due to embolic phenomenon may be challenging to echocardiographer if a comprehensive baseline examination is not performed.

Central line placement in patients with RCC with cavoatrial extension may be life-threatening due to inadvertent disruption of the thrombus by guidewire of central line leading to pulmonary artery embolization. Therefore, TEE-guided central line insertion helps in preventing the thrombus disruption. ${ }^{24}$ Due to biological propensity to invade venous channel, even preoperative imaging (MRI/CT/TEE) may not be able to tell about the exact extent and the location of the tumor at the time of surgery. Hence, intraoperative TEE provides an up-to-date assessment of tumor thrombus extension and its location. ${ }^{25,26} \mathrm{~A}$ multidisciplinary team approach is required to conduct CPB with or without deep hypothermic circulatory arrest (DHCA), depending on the extent and the adhesion of the tumor. ${ }^{25}$

Till date, there are no guidelines which recommend absolute indications for CPB in RCC; depending on the thrombus extension, adhesion to underlying structure, and on surgeon's discretion, CPB has been used for RCC with level II to level IV thrombi surgeries. ${ }^{27}$ Level IV thrombi usually require CPB for resection; however, in some cases CPB has been avoided by relying on TEE. ${ }^{24,28}$ The DHCA is very rarely required in RCC unless tumor thrombus invades the venous channel or it reaches the right ventricle. ${ }^{29}$ The DHCA provides the advantages such as a bloodless surgical field, reduces the risk of tumor fragmentation, and minimizes the chance of cellular spreading and consequent pulmonary embolization. But the usage of DHCA is associated with complications such as increased neurologic risk, coagulopathy, extended bypass time, and postoperative bleeding. ${ }^{30}$ Perioperative coagulopathy can be sometimes life-threatening in these patients. ${ }^{31}$

The TEE is a dynamic monitoring tool in perioperative period which also helps in avoiding untoward complications by real-time monitoring of thrombus during surgical manipulation. Sharma et al. reported a case of cephalad migration of the tumor thrombus to the junction of RA and IVC, causing hemodynamic instability and collapse. The tumor thrombus was detected on TEE, and the obstruction was relieved by giving traction on the right kidney, leading to normalization of hemodynamics. ${ }^{32}$

Maintaining vital organ perfusion is often challenging as these surgeries are associated with large volume shifts. Intraoperative TEE plays an important role in monitoring the volume status, cardiac performance, and in real-time monitoring to prevent intraoperative complications. The incidence of intraoperative embolism is $3.5 \% .^{10}$ However, $75 \%$ mortality occurs if it is associated with intraoperative pulmonary embolus (PE). Therefore, immediate diagnosis and treatment are very important. ${ }^{10}$ The TEE is the most sensitive and specific imaging modality for detecting intracardiac air, which may occur while thrombus excision or after reversing $\mathrm{CPB}{ }^{27}$

The TEE is useful at the end of surgery to confirm complete resection of the tumor. A TEE can be also used during nephrectomy to identify tumor embolism in the heart, in cases of severe hypotension. This has significant prognostic implications, as outcomes are largely dependent on the complete surgical removal of the tumor.

The main limitation of TEE is it is difficult to visualize the infrahepatic IVC due to anatomical divergence of the IVC and 
esophagus. ${ }^{33}$ In addition to it, peripheral branch pulmonary arteries and the left proximal pulmonary artery are poorly visualized. ${ }^{27}$ Hence, it cannot visualize emboli if they spread to branch pulmonary arteries, therefore, continuous monitoring throughout the procedure to monitor the tumor thrombus as well as assess right ventricular function and strain is warranted. ${ }^{34}$

\section{Discussion}

Intraoperative TEE is a minimally invasive low-risk procedure that can have a major impact when used in the perioperative management of patients with tumors extending into the RA. Due to the rapid progression of tumor thrombi, accurate assessment of cranial extension is crucial for optimal surgical planning. Intraoperative TEE is also useful for assessing the nature of the thrombus whether it is fragile, adherent to underlying structure, or prone to migration. Additionally, TEE is essential for continuous surveillance, hemodynamic monitoring, and to avoid intra-atrial thrombus shearing during central line insertion and guidance of resection. ${ }^{24}$ Real-time TEE visualization of the RA and IVC can help in localizing the tumor and guiding the placement of clamps on the vena cava. In one report, intraoperative TEE found residual tumor fragments in the RA after retrieval of thrombus from IVC and RA. ${ }^{35}$ A real-time monitoring with TEE helps in the rapid identification of massive pulmonary embolisms and the presence of thrombi in the pulmonary artery and provide information about right heart function. With intraoperative TEE, left ventricle volumes and potential malfunctions can be also assessed..$^{32}$

The role of intraoperative TEE varies depending on the level of tumor thrombus extension. Depending on the availability of intraoperative TEE and the expertization in TEE examination, some centers advocate the use of intraoperative TEE in all cases undergoing RCC resection with levels II and III tumor thrombi. However, some centers use routinely intraoperative TEE in known IVC involvement irrespective of the level. ${ }^{36}$ It is also recommended that perioperative echocardiographers, commonly anesthesiologists, undergo specific TEE training in order to correctly guide clinical decision-making. ${ }^{23}$ A retrospective review showed a decrease in early surgical complications from $13 \%$ to $8 \%$, which were attributed to more judicious use of CPB, probably by employing intraoperative TEE. ${ }^{6}$

Till now, no study has demonstrated superior outcomes with TEE use in treating RCC with level IV extension. This is a possible area of further research, which would help to validate future guidelines. Another potential area of future study is whether there is a decrease in postoperative complications like pulmonary embolism when intraoperative TEE is used. With the ability to ensure removal of all tumor thrombus fragments, theoretically one would expect fewer cases of postoperative embolism or cancer recurrence.

\section{Conclusion}

The TEE is an indispensable monitoring tool in the surgical management of RCC with cavoatrial extension due to its relative ease of use and noninvasive nature. Further studies are required to completely characterize the impact of using TEE in cases of RCC surgery on patients' outcome.

\section{References}

1. Siegel RL, Miller KD, Jemal A. Cancer statistics. 2015. CA Cancer J Clin 2015;65(1):5-29. DOI: 10.3322/caac. 21254.
2. Marshall VF, Middleton RG, Holswade GR, et al. Surgery for renal cell carcinoma in the vena cava. J Urol 1970;103(4):414-420. DOI: 10.1016/ s0022-5347(17)61970-0.

3. Pouliot F, Shuch B, Larochelle JC, et al. Contemporary management of renal tumors with venous tumor thrombus. J Urol 2010;184(3): 833-841. DOI: 10.1016/j.juro.2010.04.071.

4. Abreu SC, Gill IS. Renal cell carcinoma: modern surgical approach. Curr Opin Urol 2003;13(6):439-444. DOI: 10.1097/00042307-20031100000003.

5. Vogt PR, Ensner R, Prêtre R, et al. Less invasive surgical treatment of renal cell carcinomas extending into the right heart and pulmonary arteries: surgery for renal cell carcinoma. J Card Surg 1999;14(5): 330-333. DOI: 10.1111/j.1540-8191.1999.tb01004.x.

6. Blute ML, Leibovich BC, Lohse CM, et al. The mayo clinic experience with surgical management, complications and outcome for patients with renal cell carcinoma and venous tumour thrombus. BJU Int 2004;94(1):33-41. DOI: 10.1111/j.1464-410X.2004.04897.x.

7. Neves RJ, Zincke H. Surgical treatment of renal cancer with vena cava extension. Br J Urol 1987;59(5):390-395. DOI: 10.1111/j.1464-410x.1987. tb04832.x.

8. Dominik J, Moravek $\mathrm{P}$, Zacek $\mathrm{P}$, et al. Long-term survival after radical surgery for renal cell carcinoma with tumour thrombus extension into the right atrium. BJU Int 2013;111(3 Pt B):E59-E64. DOI: 10.1111/j.1464410X.2012.11515.x

9. Novick AC, Kaye MC, Cosgrove DM, et al. Experience with cardiopulmonary bypass and deep hypothermic circulatory arrest in the management of retroperitoneal tumors with large vena caval thrombi. Ann Surg 1990;212(4):472-476. DOI: 10.1097/00000658199010000-00010.

10. Shuch B, Larochelle JC, Onyia T, et al. Intraoperative thrombus embolization during nephrectomy and tumor thrombectomy: critical analysis of the University of California-Los Angeles experience. J Urol 2009;181(2):492-498. DOI: 10.1016/j.juro.2008.10.036.

11. Raj V, Alpendurada F, Christmas T, et al. Cardiovascular magnetic resonance imaging in assessment of intracaval and intracardiac extension of renal cell carcinoma. J Thorac Cardiovasc Surg 2012;144(4):845-851. DOI: 10.1016/j.jtcvs.2011.11.035.

12. Kandpal $H$, Sharma R, Gamangatti $S$, et al. Imaging the inferior vena cava: a road less traveled. Radiographics 2008;28(3):669-689. DOI: 10.1148/rg.283075101.

13. Lawrentschuk N, Gani J, Riordan R, et al. Multidetector computed tomography vs magnetic resonance imaging for defining the upper limit of tumour thrombus in renal cell carcinoma: A study and review. BJU Int 2005;96(3):291-295. DOI: 10.1111/j.1464-410X.2005.05617.x.

14. Woodruff DY, Van Veldhuizen P, Muehlebach G, et al. The perioperative management of an inferior vena caval tumor thrombus in patients with renal cell carcinoma. Urol Oncol 2013;31(5):517-521. DOI: 10.1016/j.urolonc.2011.03.006.

15. Blute ML, Boorjian SA, Leibovich BC, et al. Results of inferior vena caval interruption by greenfield filter, ligation or resection during radical nephrectomy and tumor thrombectomy. J Urol 2007;178(2):440-445. DOI: 10.1016/j.juro.2007.03.121.

16. Olkawa T, Shimazui T, Johraku A, et al. Intraoperative transesophageal echocardiography for inferior vena caval tumor thrombus in renal cell carcinoma. Int J Urol 2004;11(4):189-192. DOI: 10.1111/j.14422042.2003.00780.x.

17. Glazer A, Novick AC. Preoperative transesophageal echocardiography for assessment of vena caval tumor thrombi: a comparative study with venacavography and magnetic resonance imaging. Urology 1997;49(1):32-34. DOI: 10.1016/S0090-4295(96)00374-3.

18. Sigman DB, Hasnain JU, Del Pizzo JJ, et al. Real-time transesophageal echocardiography for intraoperative surveillance of patients with renal cell carcinoma and vena caval extension undergoing radical nephrectomy. J Urol 1999;161(1):36-38. DOI: 10.1016/S00225347(01)62054-8.

19. Wax DB, Torres A, Scher C, et al. Transesophageal echocardiography utilization in high-volume liver transplantation centers in the United 
States. J Cardiothorac Vasc Anesth 2008;22(6):811-813. DOI: 10.1053/j. jvca.2008.07.007.

20. Shine T, Feinglass NG, Leone BJ, et al. Transesophageal echocardiography for detection of propagating, massive emboli during prosthetic hip fracture surgery. lowa Orthop J 2010;30:211-214.

21. Walker $\mathrm{P}$, Bali $\mathrm{K}$, Van der Wall $\mathrm{H}$, et al. Evaluation of echogenic emboli during total knee arthroplasty using transthoracic echocardiography. Knee Surg Sports Traumatol Arthrosc 2012;20(12):2480-2486. DOI: 10.1007/s00167-012-1927-4.

22. Feigl GC, Decker K, Wurms M, et al. Neurosurgical procedures in the semisitting position: evaluation of the risk of paradoxical venous air embolism in patients with a patent foramen ovale. World Neurosurg 2014;81(1):159-164. DOI: 10.1016/j.wneu.2013.01.003.

23. Porter TR, Shillcutt SK, Adams MS, et al. Guidelines for the use of echocardiography as a monitor for therapeutic intervention in adults: a report from the American society of echocardiography. J Am Soc Echocardiogr 2015;28(1):40-56. DOI: 10.1016/j.echo.2014.09.009.

24. Fukazawa K, Gologorsky E, Naguit K, et al. Invasive renal cell carcinoma with inferior vena cava tumor thrombus: Cardiac anesthesia in liver transplant settings. J Cardiothorac Vasc Anesth 2014;28(3):640-646. DOI: 10.1053/j.jvca.2013.04.002.

25. Spelde A, Steinberg T, Patel PA, et al. Successful team-based management of renal cell carcinoma with caval extension of tumor thrombus above the diaphragm. J Cardiothorac Vasc Anesth 2017;31(5):1883-1893. DOI: 10.1053/j.jvca.2017.02.036.

26. Parissis $\mathrm{H}$, Young V. A stepwise algorithm for the surgical resection of a hyper-nephroma involving the inferior vena cava. Hellenic J Cardiol 2011;52(3):204-210.

27. Gerstein NS, Zhang R, Davis MS, et al. Lessons still being learned: acute pulmonary tumor embolus during renal cell carcinoma resection. A \& A Case Rep 2016;7(8):172-176. DOI: 10.1213/XAA.0000000000000378.

28. Ciancio G, González J, Shirodkar SP, et al. Liver transplantation techniques for the surgical management of renal cell carcinoma with tumor thrombus in the inferior vena cava: step-by-step description Eur Urol 2011;59(3):401-406. DOI: 10.1016/j.eururo.2010.07.028.

29. Nesbitt JC, Soltero ER, Dinney CPN, et al. Surgical management of renal cell carcinoma with inferior vena cava tumor thrombus. Ann Thorac Surg 1997;63(6):1592-1600. DOI: 10.1016/s00034975(97)00329-9.

30. Schimmer C, Hillig F, Riedmiller $\mathrm{H}$, et al. Surgical treatment of renal cell carcinoma with intravascular extension. Interact Cardiovasc Thorac Surg 2004;3(2):395-397. DOI: 10.1016/j.icvts.2004.02.014.

31. Ciccone MM, Cortese F, Corbo F, et al. Bemiparin, an effective and safe low molecular weight heparin: a review. Vascul Pharmacol 2014;62(1):32-37. DOI: 10.1016/j.vph.2014.03.001.

32. Sharma V, Cusimano RJ, McNama P, et al. Intraoperative migration of an inferior vena cava tumour detected by transesophageal echocardiography. Can J Anesth 2011;58(5):468-470. DOI: 10.1007/ s12630-011-9480-z.

33. Martinelli SM, Mitchell JD, McCann RL, et al. Intraoperative transesophagealechocardiography diagnosis of residual tumor fragment after surgical removal of renal cell carcinoma. Anest Analg 2008;106(6):1633-1635. DOI: 10.1213/ane.0b013e3181734147.

34. Colwell EM, Gandhi SD, labal Z, et al. Use of multimodal imaging in the management of tumor embolism from the inferior vena cava through the right heart in a patient with renal cell carcinoma. J Cardiothorac Vasc Anesth 2014;28(5):1421-1424. DOI: 10.1053/j.jvca.2014. 04.033.

35. Negi SL, Dutta V, Puri GD. Role of transesophageal echocardiography in detection of residual tumor in renal cell carcinoma extending in to right atrium. J Perioperat Echocardiog 2015;3(1):35-38. DOI: 10.5005/ jp-journals-10034-1034.

36. Chen $\mathrm{H}, \mathrm{Ng} \mathrm{V}$, Kane $\mathrm{CJ}$, et al. The role of transesophageal echocardiography in rapid diagnosis and treatment of migratory tumor embolus. Anest Analg 2004;99(2):357-359. DOI: 10.1213/01. ANE.0000133001.42742.49. 